\title{
Visible-Light-Induced Phosgenation Reaction of Amines by Oxygenation of Chloroform Using Chlorine Dioxide
}

Haruyasu Asahara, ${ }^{*, a, b}$ Nozomi Takao, ${ }^{a}$ Maiko Moriguchi, ${ }^{a}$ Tsuyoshi Inoue, ${ }^{\mathrm{a}, \mathrm{b}}$ and Kei Ohkubo ${ }^{*}, \mathrm{~b}, \mathrm{c}$

${ }^{a}$ Graduate School of Pharmaceutical Sciences, Osaka University, Yamadaoka 1-6, Suita, Osaka, $565-$ 0871, Japan.

b Institute for Open and Transdisciplinary Research Initiatives, Osaka University, 2-8 Yamadaoka, Suita, Osaka, 565-0871, Japan

${ }^{\mathrm{c}}$ Institute for Advanced Co-Creation Studies, Osaka University, 2-8 Yamadaoka, Suita, Osaka, 5650871, Japan

Email: asahara@phs.osaka-u.ac.jp, ohkubo@irdd.osaka-u.ac.jp

* TEL: +81-6-6879-8206; FAX: +81-6-6879-8205

\begin{abstract}
Carbamoyl chloride supports modern society as a building block for pharmaceuticals, agrochemicals, and polymers. Although carbamoyl chlorides are generally synthesized via the reaction of amines with phosgene $\left(\mathrm{COCl}_{2}\right)$, these applications of $\mathrm{COCl}_{2}$ have recently been avoided because of its high toxicity. Herein, we report the visible-light-induced in-situ preparation of $\mathrm{COCl}_{2}$ through the oxygenation of chloroform in the presence of chlorine dioxide, which leads to the safe constructions of carbamoyl chlorides with good-to-high yields and wide substrate scopes. In addition, this method can also be applied to the synthesis of various carbonates that are the starting materials for resins such as polycarbonates and polyurethanes.
\end{abstract}




\section{Introduction}

$\mathrm{C} 1$ chemistry is a field of industrial organic chemistry that applies one- $\mathrm{C}$ compounds such as $\mathrm{CO}, \mathrm{CO}_{2}$, $\mathrm{CH}_{4}$, and $\mathrm{CH}_{3} \mathrm{OH}$ as the raw materials for transformation reactions, which involve the interconversions of $\mathrm{C} 1$ compounds and/or C-C bond formation reactions, to produce compounds with two or more Cs. ${ }^{[1]}$ Among the one-C compounds, halogenated compounds play essential roles in $\mathrm{C} 1$ chemistry because of their high reactivities.

The phosgenation reaction, which is one of the most essential organic processes, is widely employed for fine chemical synthesis as well as resin production. ${ }^{[2]}$ Among the products obtained from the phosgenation reactions of hetero-nucleophiles, carbamoyl chloride is an essential building block that serves as a precursor for pharmaceutical and agrochemical compounds. ${ }^{[3]}$ The application of $\mathrm{COCl}_{2},{ }^{[4]}$ a simple and traditional phosgenation reagent and reactive $\mathrm{C} 1$ compound, is avoided for the synthesis of these fine chemicals because of the restrictions placed on its application due to its high toxicity. Thus, triphosgene is commonly used as an alternative reagent. ${ }^{[5]}$ Triphosgene exists in a stable crystalline form that is safer and easier to transport, store, and handle than $\mathrm{COCl}_{2}$ gas. However, in recent years triphosgene itself has been reported to be highly toxic, ${ }^{[6]}$ and an alternative method is urgently needed. The on-demand synthesis of $\mathrm{COCl}_{2}$ through the UV-light irradiation of chloroform $\left(\mathrm{CHCl}_{3}\right)$ was recently reported, ${ }^{[7]}$ which is a simple method that incorporates safe and inexpensive $\mathrm{CHCl}_{3}$ as the solvent and $\mathrm{COCl}_{2}$ precursor. This method requires high-energy UV light, which induces the decomposition of $\mathrm{COCl}_{2}$ as the product as well as the versatility of the substrate. However, although reactions with nucleophiles such as alcohols proceed efficiently, they are not suitable for the synthesis of carbamoyl chlorides from light-unstable amines.

On the other hand, we reported the $\mathrm{C}-\mathrm{H}$ oxygenation reaction of methane $\left(\mathrm{CH}_{4}\right)$ through the light activation of chlorine dioxide radical $\left(\mathrm{ClO}_{2}{ }^{\circ}\right){ }^{[8]}$ In these oxidation reactions, the chlorine radical $\left(\mathrm{Cl}^{\circ}\right)$ generated from the $\mathrm{ClO}_{2}{ }^{\circ}$ gas upon light activation cleaved the $\mathrm{C}-\mathrm{H}$ bond. The $\mathrm{C}-\mathrm{H}$ bond dissociation energy of $\mathrm{CH}_{4}$ is $104 \mathrm{kcal} \mathrm{mol}^{-1}$, which was higher than that of $\mathrm{CHCl}_{3}\left(95.7 \mathrm{kcal} \mathrm{mol}^{-1}\right) .{ }^{[9]}$ These results prompted us to investigate the generation of $\mathrm{COCl}_{2}$ through the oxygenation of $\mathrm{CHCl}_{3}$ with $\mathrm{ClO}_{2}{ }^{\circ}$ 
under visible-light irradiation, because $\mathrm{ClO}_{2}{ }^{\circ}$ has a strong absorption band in the visible-light region. Herein, we report the synthesis of carbamoyl chlorides with wide substrate scopes via phosgenation reactions using visible-light irradiation $(\lambda>400 \mathrm{~nm})$, without decomposing $\mathrm{COCl}_{2}$ and further deriving products such as carbamoyl chloride. (Scheme 1).

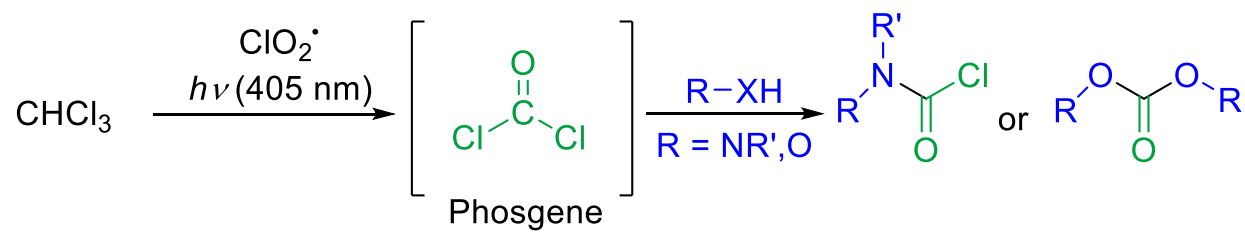

Scheme 1. In-situ $\mathrm{COCl}_{2}$ preparation through $\mathrm{CHCl}_{3}$ oxygenation using visible-light activated $\mathrm{ClO}_{2}{ }^{\circ}$, and further reactions with hetero-nucleophiles to form carbamoyl chloride or carbonate products. 


\section{Results and Discussion}

As shown in Figure 1, an H-shaped reaction glass tube (COware) was employed as the two-chamber system. ${ }^{[10]}$ One side of the system (Chamber A, $5 \mathrm{~mL}$ ) contained an aqueous $\mathrm{ClO}_{2}{ }^{\circ}$ solution prepared through the mixing of sodium chlorite with $\mathrm{HCl}$. The other side of the system (Chamber $\mathrm{B}, 2 \mathrm{~mL}$ ) contained a $\mathrm{CHCl}_{3}$ solution with the substrate. When visible-light irradiation from an LED light $(\lambda=$ $405 \mathrm{~nm}$ ) was applied to the whole vessel, gaseous $\mathrm{ClO}_{2}{ }^{\circ}$ was generated from Chamber $\mathrm{A}$. The generated $\mathrm{ClO}_{2}{ }^{\circ}$ gas traveled through the glass-tube bridge connecting the two chambers, to dissolve in the $\mathrm{CHCl}_{3}$ solution in Chamber B. After 40 min of visible-light irradiation, when the deuterated $\mathrm{CHCl}_{3}$ was used without substrate, $\mathrm{COCl}_{2}$ was generated in the $\mathrm{CHCl}_{3}$ and confirmed through an observation of the characteristic signal of its carbonyl carbon at $143 \mathrm{ppm}$ in its ${ }^{13} \mathrm{C}$ NMR spectrum. (Figure S1).

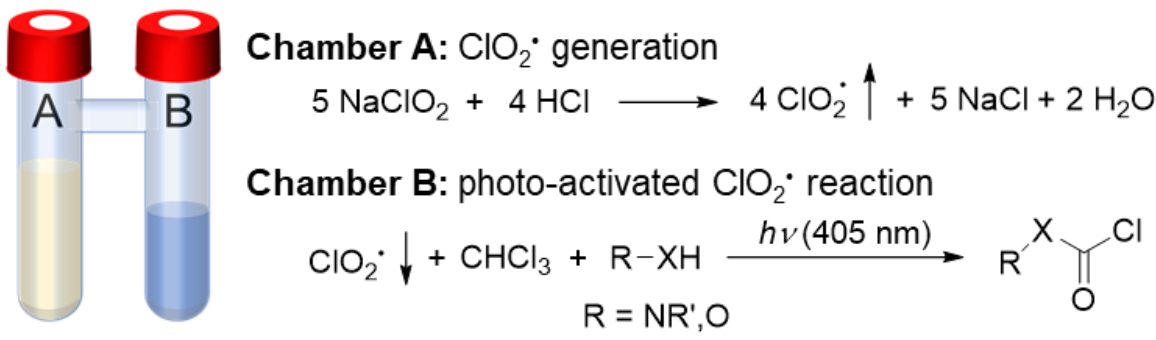

Figure 1. Schematic illustration of in situ phosgenation process using two chamber system.

Encouraged by this result, we commenced the study by employing $N$-methylaniline 1a as the model amine substrate for reaction condition optimization (Table 1). The target carbamoyl chloride $\mathbf{2 a}$ was obtained with an $84 \%$ NMR yield when 4 equivalents ${ }^{[11]}$ of $\mathrm{ClO}_{2}{ }^{\circ}$ and 5 equivalents of $\mathrm{NEt}_{3}$ as the base were applied under the visible-light irradiation of $90 \mathrm{~mW} \mathrm{~cm}^{-2}$ LED at room temperature (Entry 1). A decrease in the visible-light intensity of the reaction decreased the $\mathbf{2 a}$ yield to $78 \%$ (Entry 2), and the reaction did not occur under the dark condition (Entry 3). An increase in $\mathrm{ClO}_{2}{ }^{\bullet}$ effectively afforded $\mathbf{2 a}$ with a $93 \%$ yield (Entry 4$)$. On the other hand, the yield of 2a decreased slightly and a small amount of the urea 3a byproduct was obtained when the $\mathrm{ClO}_{2}{ }^{\circ}$ decreased (Entry 5). A brief base screening revealed that diisopropylethylamine (DIPEA) was optimal, and the applications of less than two equivalents of DIPEA resulted in poor yields (Entries 7-10). Furthermore, we investigated the optimal 
conditions to obtain urea $\mathbf{3 a}$, and the best results were obtained when $\mathrm{ClO}_{2}{ }^{\circ}$ was decreased to one equivalent and pyridine was used as the base (Entry 13). It is considered that the pyridine activates the carbamoyl chloride and promotes the addition of a second amine. Because a change in the amount of $\mathrm{ClO}_{2}{ }^{\circ}$ or a decrease in the amount of pyridine led to a decrease in the 3a yield, Entry 13 was chosen as the optimal reaction condition for urea production.

Table 1. Optimization of reaction conditions.[a]

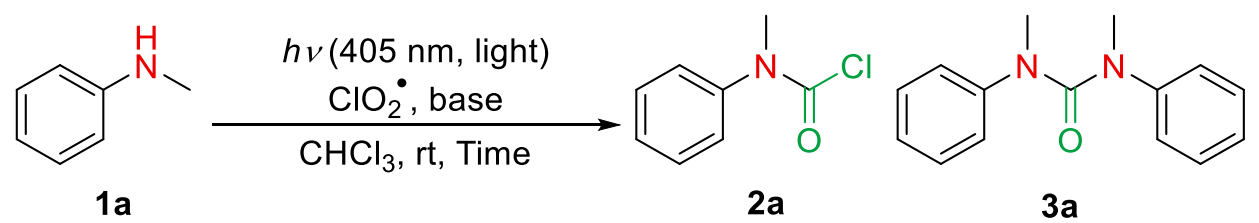

\begin{tabular}{|c|c|c|c|c|c|c|c|}
\hline \multirow{3}{*}{$\frac{\text { Entry }}{1}$} & \multirow{3}{*}{$\frac{\begin{array}{c}\text { Light } \\
\left(\mathrm{mW} / \mathrm{cm}^{2}\right)\end{array}}{90}$} & \multirow{3}{*}{$\begin{array}{c}\begin{array}{c}\text { Time } \\
(\min )\end{array} \\
40\end{array}$} & \multirow{3}{*}{$\frac{\begin{array}{c}\mathrm{ClO}_{2}{ }^{\circ} \\
\text { (equiv.) }\end{array}}{4}$} & \multirow{2}{*}{\multicolumn{2}{|c|}{$\begin{array}{l}\text { Base } \\
\text { (equiv.) }\end{array}$}} & \multicolumn{2}{|c|}{ NMR Yield (\%) } \\
\hline & & & & & & \multirow{2}{*}{$\frac{2 a}{84}$} & \multirow{2}{*}{$\frac{3 a}{0}$} \\
\hline & & & & $\mathrm{NEt}_{3}$ & (5) & & \\
\hline 2 & 30 & 90 & 4 & $\mathrm{NEt}_{3}$ & (5) & 78 & 0 \\
\hline 3 & Dark & 900 & 4 & $\mathrm{NEt}_{3}$ & (5) & 0 & 0 \\
\hline 4 & 90 & 60 & 8 & $\mathrm{NEt}_{3}$ & (5) & 93 & 0 \\
\hline 5 & 90 & 30 & 2 & $\mathrm{NEt}_{3}$ & (5) & 74 & 4 \\
\hline 6 & 90 & 60 & 8 & Pyridine & (5) & 61 & 0 \\
\hline 7 & 90 & 60 & 8 & DIPEA & (5) & 99 & 0 \\
\hline 8 & 90 & 60 & 8 & DIPEA & (3) & 95 & 0 \\
\hline 9 & 90 & 60 & 8 & DIPEA & $(2)$ & 63 & 0 \\
\hline 10 & 90 & 40 & 4 & DIPEA & (3) & 83 & 0 \\
\hline 11 & 90 & 60 & 8 & - & & 42 & 0 \\
\hline 12 & 90 & 30 & 1 & DIPEA & (5) & 16 & 31 \\
\hline 13 & 90 & 30 & 1 & Pyrdine & (5) & 0 & 67 \\
\hline 14 & 90 & 40 & 2 & Pyrdine & (5) & 0 & 47 \\
\hline 15 & 90 & 20 & 0.5 & Pyrdine & (5) & 3 & 39 \\
\hline 16 & 90 & 30 & 1 & Pyrdine & (3) & 0 & 34 \\
\hline
\end{tabular}

[a] Reaction conditions: $1 \mathrm{a}(0.2 \mathrm{mmol}, 0.1 \mathrm{M})$, room temperature.

Using the optimized reaction conditions, we investigated the substrate scopes of the phosgenation reactions of $N$-nucleophiles (Figure 2). First, the scopes of different aromatic amine (aniline) derivatives were examined. Both anilines with electron-donating and electron-withdrawing substituents afforded their corresponding carbamoyl chlorides (2b and $\mathbf{2 c}$ ) in good yields. Interestingly, 
allyl-substituted aniline 1d and iminostilbene 1e underwent phosgenation reactions to afford their desired products in moderate yields and without side reactions such as chlorination of the double alkenyl $\mathrm{C}=\mathrm{C}$ bond. However, trace amounts of the product were detected when the diphenylamine $\mathbf{1 f}$ was used as the substrate. This is partly owing to the lower nucleophilicity of the $\mathbf{1 f}$ compared with those of the $N$-methyl anilines 1a-c. ${ }^{[12]}$ In the case of the conformationally-restricted cyclic derivatives, an unknown byproduct was observed and was likely because of its higher reactivity. Hence, the desired products $\mathbf{2 g}$ and $\mathbf{2 h}$ were obtained in high yields through a decrease of $\mathrm{ClO}_{2}{ }^{\circ}$ to 4 equivalents. Aliphatic amines were compatible in the reactions and afforded the related products in moderate-to-good yields. The phosgenation reactions of dibutyl amine $\mathbf{1 i}$ and the cyclic amines $\mathbf{1} \mathbf{j}$ and $\mathbf{1} \mathbf{k}$ achieved 99,83 , and $58 \%$ yields, respectively. ${ }^{[13]}$ The proline derivative $\mathbf{1 1}$ also afforded the desired product in a moderate yield. The benzyl-substituted amine $\mathbf{1 m}$ and the tetrahydroisoquinoline derivatives $\mathbf{1 n}$ and $\mathbf{1 0}$ were well tolerated under the reaction conditions, and provided the desired products in excellent yields. Notably, the $\mathbf{2 0}$ product formed through this method is a key precursor of solifenacin, a competitive cholinergic receptor antagonist. In addition, we tested this method during the late-stage phosgenation reactions of structurally complex pharmaceutical samples. Both of the fluoroquinolone antibiotics, norfloxacin and gatifloxacin, afforded the desired products in high yields and without any detectable side products. When the substrates with nitrogen and oxygen nucleophiles in the same molecule were used, the corresponding cyclic products with inserted carbonyl groups 4-6 were obtained in high yields. The heterocyclic skeletons obtained have been investigated extensively for the developments of various pharmaceuticals and pesticides. ${ }^{[14]}$

We also explored the scopes of these reactions by replacing the nitrogen nucleophiles with oxygen nucleophiles (phenols and alcohols, Figure 3). The process for the $N$-methyl aniline was applied to the phenols, and for all their cases, the carbonates $\mathbf{8 a}-\mathbf{d}$ were obtained in quantitative yields. In addition, the desired carbonates were obtained using the fluorine-substituted alcohols as the substrates, although their yields were slightly lower. Diols such as the ethylene glycol, propylene glycol, and catechol derivatives also afforded their corresponding cyclic carbonates $(\mathbf{9 a}, \mathbf{b}$, and $\mathbf{1 0})$ at high yields. Different 
types of carbonates, including diaryl, dialkyl, and cyclic carbonates, are essential in industry and are employed in a broad range of applications ${ }^{[15]}$ such as their employments as the starting materials for resin (polycarbonates and polyurethanes) manufacturing, and have recently attracted considerable attention as sustainable process feedstocks. ${ }^{[16]}$

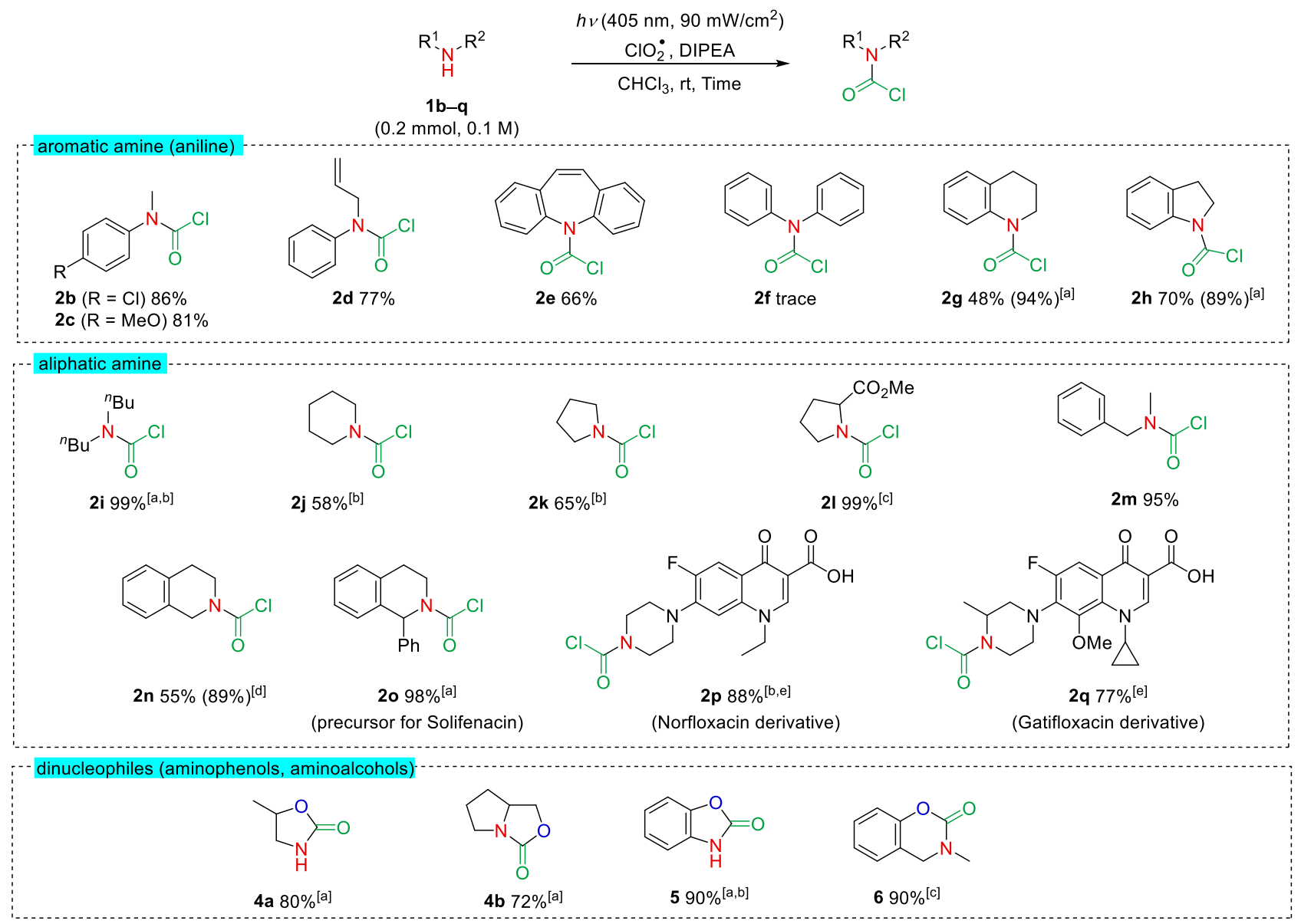

Figure 2. Substrate scopes of the phosgenation reactions of $N$-nucleophiles. The reactions conditions: amine $10.2 \mathrm{mmol}(0.1 \mathrm{M}), \mathrm{ClO}_{2} \cdot$ (8 equiv.), DIPEA (3 equiv.) at room temperature for $60 \mathrm{~min}$. Isolated yields recorded for [a] $\mathrm{ClO}_{2}{ }^{\circ}$ (4 equiv.), 40 min; [b] reactions conducted in $\mathrm{CDCl}_{3}$ instead of $\mathrm{CHCl}_{3} .{ }^{1} \mathrm{H}$ NMR yields obtained based on the internal standard [c] $\mathrm{ClO}_{2}{ }^{\circ}$ (4 equiv.), DIPEA (5 equiv.), $40 \mathrm{~min}$; [d] amine $10.1 \mathrm{mmol}(0.02 \mathrm{M}), 40$ min; [e] amine $10.1 \mathrm{mmol}(0.05 \mathrm{M}), \mathrm{ClO}_{2} \cdot$ (4 equiv.), $30 \mathrm{~min}$. 


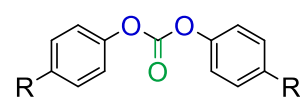

$8 \mathbf{a}(\mathrm{R}=\mathrm{MeO}) 99 \%$

8b $(\mathrm{R}=\mathrm{H}) \quad 98 \%$

8c $(\mathrm{R}=\mathrm{Cl}) \quad 99 \%$

8d $\left(\mathrm{R}=\mathrm{NO}_{2}\right) \quad 97 \%$

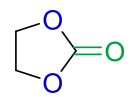

9a $99 \%{ }^{[b]}$

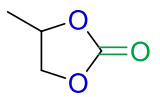

9b $99 \%[b]$
$\mathrm{F}_{3} \mathrm{C} \smile \mathrm{O}_{\mathrm{O}} \mathrm{O}_{2} \smile \mathrm{CF}_{3}$

8 e $72 \%$ [a]

${ }_{\mathrm{CF}_{3} \mathrm{O}}^{\mathrm{F}_{3} \mathrm{C}}{ }_{\mathrm{CF}_{3}}^{\mathrm{O}}$

8f $91 \%$ [a]<smiles>O=c1oc2ccccc2o1</smiles>

$1090 \%^{[b]}$

Figure 3. Substrate scopes of the phosgenation reactions of $O$-nucleophiles. The reactions conditions: phenols or alcohols $60.2 \mathrm{mmol}(0.1 \mathrm{M}), \mathrm{ClO}_{2}{ }^{\circ}$ (4 equiv.), DIPEA (5 equiv.) at room temperature for $40 \mathrm{~min}$; [a] isolated yields when reactions were conducted in $\mathrm{CDCl}_{3}$ instead of $\mathrm{CHCl}_{3}$; [b] ${ }^{1} \mathrm{H}$ NMR yields based on the internal standard of DIPEA (3 equiv.).

To investigate the reaction mechanism of the generation of $\mathrm{COCl}_{2}$ from chloroform by our method, we conducted a control experiment shown in Scheme 2. Ethylene glycol, which reacts with $\mathrm{COCl}_{2}$ at a 1:1 ratio, was employed as the substrate and reacted with $\mathrm{ClO}_{2}{ }^{\circ}(0.5$ equiv. $)$ to afford a cyclic carbonate with a $61 \%$ yield. This result indicates that an equivalent amount of $\mathrm{ClO}_{2}{ }^{\circ}$ is not required for $\mathrm{COCl}_{2}$ formation.

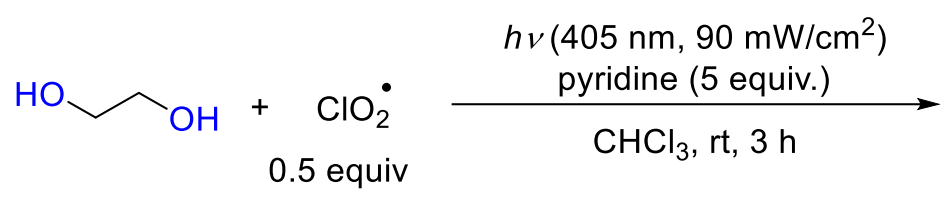

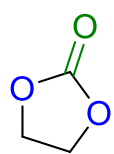

9a $61 \%$

Scheme 2. Mechanistic experiment.

Furthermore, the product yields of carbonate 9a were determined (Figure 4) with respect to the reaction times in $\mathrm{CHCl}_{3}$ and $\mathrm{CDCl}_{3}$ under the same reaction conditions as in Scheme 2. It is worth noting that a significant induction period was observed when the reaction was conducted in $\mathrm{CDCl}_{3}$. It has been reported that the difference in bond energies between $\mathrm{Cl}_{3} \mathrm{C}-\mathrm{H}$ and $\mathrm{Cl}_{3} \mathrm{C}-\mathrm{D}$ is $6.0 \mathrm{kcal} \mathrm{mol}{ }^{-1}{ }^{[17]}$ These results indicate that hydrogen abstraction from $\mathrm{Cl}_{3} \mathrm{CH}$ is the rate-limiting step in this reaction. 


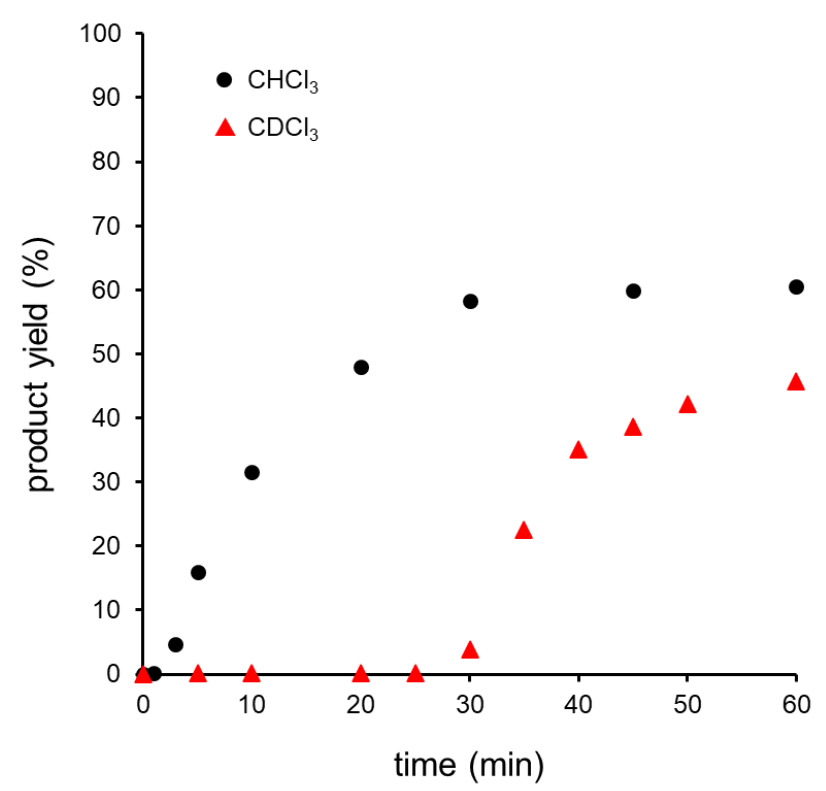

Figure 4. Variation in product yield against reaction time for samples in $\mathrm{CHCl}_{3}$ (black circle) and $\mathrm{CDCl}_{3}$ (red triangle). The reaction conditions: ethylene glycol $0.4 \mathrm{mmol}(0.1 \mathrm{M}), \mathrm{ClO}_{2}{ }^{\circ}(0.5$ equiv.), and pyridine (5 equiv.) at room temperature. The product yields were determined using ${ }^{1} \mathrm{H}$ NMR.

Based on the experimental results obtained, the DFT calculations performed (M06-2x/6-311++G(d,p) level of theory; see the Supporting Information), and previous reports, ${ }^{[17]}$ a plausible reaction mechanism is presented in Scheme 3. The visible-light activation of $\mathrm{ClO}_{2}{ }^{\circ}$ yields chlorine radicals $\left(\mathrm{Cl}^{\circ}\right)$ and singlet oxygen molecules $\left({ }^{1} \mathrm{O}_{2}{ }^{*}\right)$ through bond rearrangements from $\mathrm{Cl}-\mathrm{O}-\mathrm{Cl}$ to $\mathrm{Cl}-\mathrm{O}-\mathrm{O}$ bonds. ${ }^{[8]}$ The generated $\mathrm{Cl}^{\bullet}$ abstracts hydrogen from $\mathrm{Cl}_{3} \mathrm{C}-\mathrm{H}$ to form a trichloromethyl radical $\left(\mathrm{Cl}_{3} \mathrm{C}^{*}\right)$ and $\mathrm{HCl}$. This process proceeds more easily than methane oxidation, as indicated by the $\mathrm{C}-\mathrm{H}$ bond energies $\left(\mathrm{H}_{3} \mathrm{C}-\mathrm{H}: 104 \mathrm{kcal} \mathrm{mol}^{-1}, \mathrm{Cl}_{3} \mathrm{C}-\mathrm{H}: 95.7 \mathrm{kcal} \mathrm{mol}^{-1}\right) \cdot{ }^{[9]} \mathrm{In}$ fact, the energy difference $(\Delta E)$ for this process estimated from DFT calculations is negative $\left(-3.3 \mathrm{kcal} \mathrm{mol}^{-1}\right)$. However, this reaction step is energetically unfavorable for $\mathrm{CDCl}_{3}$ compared with $\mathrm{CHCl}_{3}$, because of its relatively higher bond energy. This could have resulted in a remarkable induction period. The radical intermediate $\mathrm{CCl}_{3}{ }^{\bullet}$ then combines with oxygen to produce the peroxyl radical $\mathrm{CCl}_{3} \mathrm{OO}$. The calculated $\Delta E$ values for the formations of $\mathrm{CCl}_{3} \mathrm{OO}^{*}$ from the singlet and triplet $\mathrm{O}_{2}$ are -60.5 and $-23.1 \mathrm{kcal} \mathrm{mol}^{-1}$, respectively. Hence, once $\mathrm{CCl}_{3}{ }^{\circ}$ is formed, it can rapidly react with both the singlet and triplet $\mathrm{O}_{2}$ to produce the peroxyl radical. $\mathrm{CCl}_{3} \mathrm{OO}^{\circ}$ gives an alkoxy radical $\left(\mathrm{CCl}_{3} \mathrm{O}^{\circ}\right)$ through the desorption of $\mathrm{O}_{2}$ via a Russel- 
type mechanism, and the $\Delta E$ value for this process is estimated to be $-4.9 \mathrm{kcal} \mathrm{mol}^{-1}$. There are two possible reaction pathways for the generation of $\mathrm{CCl}_{3} \mathrm{O}^{\circ}$; the first pathway is $\mathrm{COCl}_{2}$ formation through the regeneration of $\mathrm{Cl}^{\circ}$, and the second pathway is the mechanism of hydrogen abstraction from $\mathrm{CHCl}_{3}$ to form $\mathrm{Cl}_{3} \mathrm{C}^{\bullet}$. Both pathways are estimated to be exothermic with $\Delta E$ values of -16.1 and $-14.8 \mathrm{kcal}$ mol $^{-1}$, respectively. The regenerated $\mathrm{Cl}^{\cdot}$ and $\mathrm{CCl}_{3}{ }^{\circ}$ are recycled to produce $\mathrm{COCl}_{2}$ until the radical chain is terminated. In addition, the generated $\mathrm{CCl}_{3} \mathrm{OH}$ yields $\mathrm{COCl}_{2}$ along with $\mathrm{HCl}$, and the $\Delta E$ value for this step is also negative $\left(-4.5 \mathrm{kcal} \mathrm{mol}^{-1}\right)$. Thus, all the steps after the photochemical generation of $\mathrm{Cl}^{\circ}$, as shown in Scheme 3, are exothermic in nature and energetically favorable as a radical chain reaction.

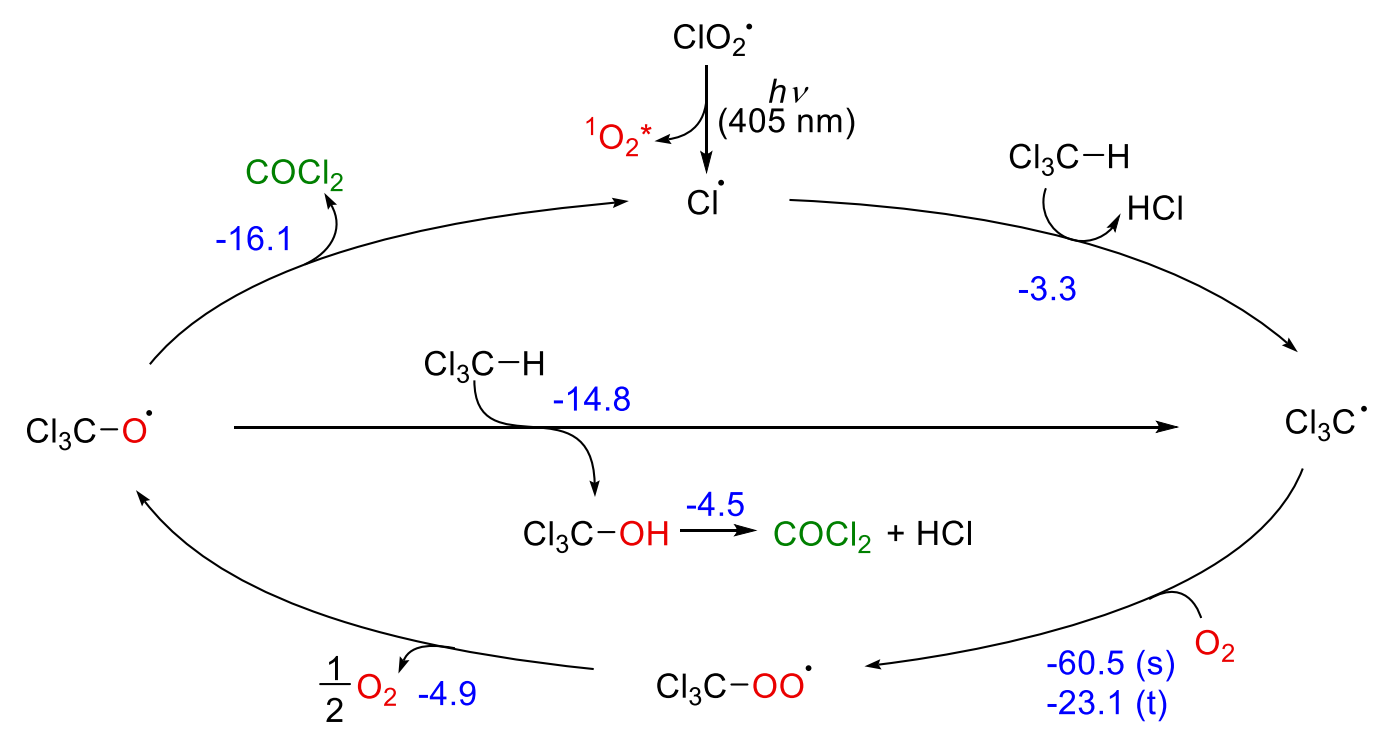

Scheme 3. Plausible radical chain mechanism for the generation of phosgene through the oxygenation of $\mathrm{CHCl}_{3}$ using visible-light-activated $\mathrm{ClO}_{2}{ }^{\circ}$. The blue numbers indicate the $\Delta E$ values $\left(\mathrm{kcal} \mathrm{mol}^{-1}\right)$ estimated using DFT calculations.

The stoichiometric equation for this oxygenation reaction is given by Equation (1). Two $\mathrm{CHCl}_{3}$ molecules react with one $\mathrm{O}_{2}$ molecule to produce two $\mathrm{COCl}_{2}$ molecules. This means that the $\mathrm{ClO}_{2}{ }^{\circ}$ acts as an initiator in the radical chain cycle and as an $\mathrm{O}_{2}$ source for $\mathrm{COCl}_{2}$ formation.

$2 \mathrm{CHCl}_{3}+\mathrm{O}_{2} \longrightarrow 2 \mathrm{COCl}_{2}+2 \mathrm{HCl}$ 


\section{Conclusion}

We have developed a visible-light-induced $\mathrm{COCl}_{2}$ generation method using $\mathrm{CHCl}_{3}$ and sodium chlorite as the starting materials, which are inexpensive and easy to handle. Various carbamoyl chlorides can be synthesized safely and efficiently via the phosgenation reactions of amines using $\mathrm{COCl}_{2}$ generated in situ. This is an excellent method that can be applied to a wide range of substrates, including anilines and aliphatic amines, as well as pharmaceutical compounds with nucleophilic nitrogen atoms. In addition, this phosgenation method was successfully applied to carbonate synthesis from phenols and alcohols. This novel phosgenation system is an alternative to the classical method that involves the use of a hazardous reagent. 
[1] a) C. Mesters, Annu. Rev. Chem. Biomol. Eng. 2016. 7, 223-238. b) W. Zhou, K. Cheng, J. Kang, C. Zhou, V. Subramanian, Q. Zhang, Y. Wang, Chem. Soc. Rev., 2019, 48, 3193-3228. c) Y. Liu, D. Deng, X. Bao, Chem, 2020, 6, 2497-2514.

[2] a) H. Babad, A. G. Zeiler, Chem. Rev. 1973, 73, 75-91; b) L. Cotarca, H. Eckert, in Phosgenations-A Handbook, Wiley-VCH, Weinheim, 2003.

[3] a) D. R. Lide, in CRC Handbook of Chemistry and Physics, 87th ed., CRC Press, Boca Raton, FL 2006-2007, p 4002; b) P. Jaeger, C. N. Rentzea, H. Kieczka, in Ullmann's encyclopedia of industrial chemistry, Wiley-VCH, Weinheim, Germany 2012; c) K. Adeppa, D. C. Rupainwar, K. Misra, Can. J. Chem. 2010, 88, 1277-1280; d) P. Jaeger, C. N. Rentzea, H. Kieczka, in Ullmann's encyclopedia of industrial chemistry, Wiley-VCH, Weinheim, Germany 2014, pp 399-406, e) M. Shrestha, X. Wu, W. Huang, J. Qu, Y. Chen, Org. Chem. Front. 2021, 8, 4024-4045.

[4] Global Phosgene Outlook 2016-2021, Gen Consulting Company, 2016

[5] a) H. Eckert, B. Forster, Angew. Chem. Int. Ed. 1987, 26, 894-895; b) L. Cotarca, P. Delogu, A. Nardelli, V. Sunjic, Synthesis 1996, 553-576; c) W. Su, W. Zhong, G. Bian, X. Shi, J. Zhang, Org. Prep. Proced. Int. 2004, 36, 499-547; d) M. O. Ganiu, B. Nepal, J. P. Van Houten, R. Kartika, Tetrahedron 2020, 76, 131553.

[6] H. Eckert, Chim. Oggi. 2011, 29, 40-46.

[7] a) Y. Kuwahara, A. Zhang, H. Soma, A. Tsuda, Org. Lett. 2012, 14, 3376-3379; b) F. Liang, M. Yanai, Y. Suzuki, A. Tsuda, Org. Lett. 2020, 22, 3566-3569; c) Y. Hashimoto, S. Hosokawa, F. Liang, Y. Suzuki, N. Dai, G. Tana, K. Eda, T. Kakiuchi, T. Okazoe, H. Harada, A. Tsuda, J. Org. Chem. 2021, $86,14,9811-9819$.

[8] a) K. Ohkubo, K. Hirose, Angew. Chem., Int. Ed. 2018, 57, 2126- 2129; b) K. Ohkubo, H. Asahara, T. Inoue, A. Tsuda, Chem. Commun. 2019, 55, 4723-4726.

[9] J. A. Kerr, Chem. Rev. 1966, 66, 465-500.

[10] For examples using two-chamber system, see: a) X. Jia, S. Kramer, T. Skrydstrup, Z. Lian, Angew. Chem. Int. Ed. 2021, 60, 7353-7359; b) L. Chen, M. Zhou, L. Shen, X. He, X. Li, X. Zhang, Org. Lett. 2021, 23, 4991-4996; c) K. Nozawa-Kumada, K. Noguchi, T. Akada, M. Shigeno, Y. Kondo, Org. Lett. 2021, 23, 6659-6663.

[11] Based on the amount of sodium nitrite $\left(0.8\right.$ equivalent of $\mathrm{ClO}_{2} \cdot$ was generated from $\mathrm{ClO}_{2}^{-}$by dismutation reaction).

[12] J. J. Campbell, S. A. Glover, J. Chern. Research (S),1999, 474-475.

[13] Reaction was conducted in $\mathrm{CDCl}_{3}$ due to the low boiling point of the substrate. In addition, the concentration of amines $\mathbf{1} \mathbf{j}, \mathbf{k}$ was reduced to suppress the formation of corresponding urea.

[14] a) H. Ucar, K. Van derpoorten, S. Cacciaguerra, S. Spampinato, J. P. Stables, P. Depovere, M. Isa, B. Masereel, J. Delarge, J. H. Poupaert, J. Med. Chem. 1998, 41, 1138-1145; b) D. Chaturvedi, Tetrahedron, 2012, 68, 15-45; c) K. I. Reddy, C. Aruna, S. K. Babu, V. Vijayakumar, M. Manisha, J. P. Sridevi, P. Yogeeswari, D. Sriram, RSC Adv. 2014, 4, 59594-59602; d) K. E. Ryu, B. R. Kim, G. H. Sung, H. J. Yoon, Y.-J. Yoon, Synlett 2015, 26, 1985-1990; e) Y. Chen, C. A. Hone, B. Gutmann, 
C. O. Kappe, Org. Process Res. Dev. 2017, 21, 1080-1087; f) J. Lee, J. Lee, H. Jung, D. Kim, J. Park, S. Chang, J. Am. Chem. Soc. 2020, 142, 12324-12332.

[15] a) F. Bigi, R. Maggi, G. Sartori, Green Chem. 2000, 2, 140-148; b) M. Carafa, V. Melea, E. Quaranta, Green Chem. 2012, 14, 217-225; c) S. Huang, B. Yan, S. Wang, X. Ma, Chem. Soc. Rev., 2015, 44, 3079-3116; d) E. R. Baral, J. H. Lee, J. G. Kim, J. Org. Chem. 2018, 83, 11768-11776.

[16] a) J. Shang, S. Liu, X. Ma, L. Lu, Y. Deng, Green Chem. 2012, 14, 2899-2906; b) O. Kreye, H. Mutlu, M. A. R. Meier, Green Chem., 2013, 15, 1431-1455; c) Z. Dobi, B. N. Reddy, E. Renders, L. Van Raemdonck, C. Mensch, G. De Smet, C. Chen, C. Bheeter, S. Sergeyev, W. A. Herrebout, B. U. W. Maes, ChemSusChem 2019, 12, 3103-3114; d) M. Soccio, R. Mazzoni, C. Lucarelli, S. Quattrosoldi, A. Cingolani, M. Fiorini, N. Lotti, T. Tabanelli, ACS Sustainable Chem. Eng., 2020, 8, 15640-15650.

[17] a) T. Alapi, A. Dombi, Chemosphere, 2007, 67, 693-701. b) A. J. Seidl, L. R. Cohen, L. A. Peña, P. E. Hoggard, Photochem. Photobio. Sci., 2008, 7, 1373-1377. 